\title{
Localization of A Novel Autosomal Recessive Non-Syndromic Hearing Impairment Locus (DFNB38) to 6q26-q27 in a Consanguineous Kindred from Pakistan
}

\author{
Muhammad Ansara ${ }^{a}$ Mohammad Ramzan ${ }^{a}$ Thanh L. Pham ${ }^{b}$ Kai Yan ${ }^{b}$ \\ Syed Muhammad Jamal a Sayedul Haque ${ }^{a}$ Wasim Ahmad ${ }^{a}$ \\ Suzanne M. Leal ${ }^{b}$ \\ aDepartment of Biological Sciences, Quaid-I-Azam University Islamabad, Pakistan; \\ bDepartment of Molecular and Human Genetics, Baylor College of Medicine, Houston Tex., USA
}

\section{Key Words}

Autosomal recessive hearing impairment - DFNB38 .

Gene mapping • Pakistan • 6q26-q27

\begin{abstract}
For autosomal recessive nonsyndromic hearing impairment over 30 loci have been mapped and 19 genes have been identified. DFNB38, a novel locus for autosomal recessive nonsyndromic hearing impairment, was localized in a consanguineous Pakistani kindred to 6q26-q27. The affected family members present with profound prelingual sensorineural hearing impairment and use sign language for communications. Linkage was established to microsatellite markers located on chromosome 6q26q27 (Multipoint lod score 3.6). The genetic region for DFNB38 spans $10.1 \mathrm{cM}$ according to the Marshfield genetic map and is bounded by markers D6S980 and D6S1719. This genetic region corresponds to $3.4 \mathrm{MB}$ on the sequence-based physical map.
\end{abstract}

Copyright $@ 2003$ S. Karger AG, Basel

\section{Introduction}

Hearing loss is a common sensory disorder in the human population. The incidence of congenital hearing loss is estimated at 1 in 1,000 births, of which approximately $60 \%$ of cases are attributed to genetic factors [1, 2]. Approximately, $70 \%$ of hearing impairments which are due to genetic factors are classified as nonsyndromic. For syndromic hearing loss the pathology varies widely in contrast to nonsyndromic hearing loss where the defect is usually sensorineural.

Nonsyndromal hearing impairment in humans is genetically heterogeneous. To date over 30 loci for autosomal recessive nonsyndromic hearing loss have been mapped and 19 genes have been identified [3]. This extreme genetic heterogeneity suggests that there are many different processes that can malfunction within the inner ear to cause hearing loss [4].

\section{Methods}

Family History

Before the onset of the study, approval was obtained from the Quaid-I-Azam University Institutional Review Board. Informed consent was obtained from all family members who participated in

Dr. Suzanne M. Leal

Department of Molecular and Human Genetics, Baylor College of Medicine

One Baylor Plaza

Houston TX, 77030 (USA)

Tel. +1 713798 4011, Fax +1 713798 4373, E-Mail sleal@bcm.tmc.edu
Fax + 41613061234

E-Mail karger@karger.ch

www.karger.com
Accessible online at: www. karger.com/hhe 


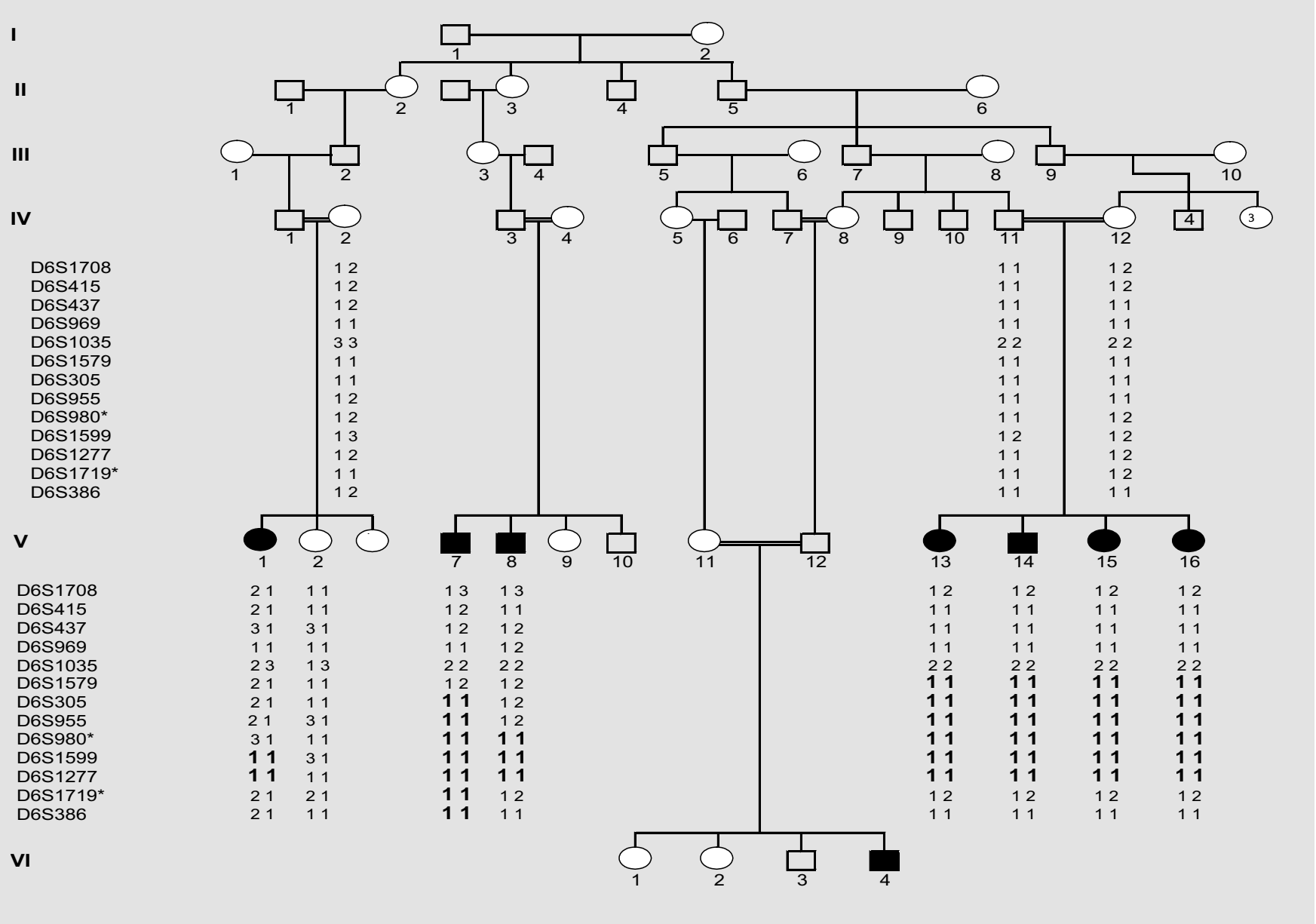

Fig. 1. Drawing of pedigree 4004 that segregates the DFNB38 locus. The sexes of some of the family members have been changed to protect the anonymity of the family. Black symbols represent individuals with hearing impairment and clear symbols represent unaffected individuals. Haplotypes for the most closely linked STRPs are shown below each symbol. When it is possible to distinguish the first haplotype displayed is the paternal haplotype. The region of homozygosity for hearing impaired individuals is shown in bold. The markers D6S980 and D6S1719 which flank the critical region are denoted by a star.

the study. The pedigree structure is based upon interviews with multiple family members. Pedigree 4004 (fig. 1) from Pakistan provided convincing evidence of an autosomal recessive mode of inheritance. Personal interviews with various family members clarified consanguineous relationships. Spouses IV.1 and IV.2 and IV. 3 and IV.4 are distantly related cousins; however their exact relationship could not be confirmed. All affected individuals have prelingual profound hearing impairment that affects all frequencies and use sign language as their means of communication. All hearing impaired family members underwent a physical examination for defects in ear morphology, vision, mental retardation and other clinical features that could indicate that the hearing impairment belonged to a syndrome. There was no evidence that the hearing impairment in this kindred is syndromal or that there is gross vestibular involvement.

\section{Genotyping}

Venous blood samples were obtained from 11 family members including 7 individuals who are hearing impaired. Genomic DNA was extracted from whole blood following a standard protocol [5]. A genome scan was carried out on 11 DNA samples at the Center for Inherited Disease Research (CIDR). A total of 390 fluorescently labeled simple tandem repeat (STRP) markers were genotyped. These markers are spaced $\sim 10 \mathrm{cM}$ apart and are located on the 22 autosomes and the $\mathrm{X}$ and $\mathrm{Y}$ chromosomes.

\section{Linkage Analysis}

Two-point linkage analysis was carried out on all autosomal markers from the genome scan by means of the MLINK program of the FASTLINK computer package [6]. Multipoint analysis was performed using ALLEGRO [7] utilizing map distances from the 
Table 1. Two-point lod score results between the DFNB38 locus and chromosome 6 markers; also displayed are the genetic and sequencebased physical map distances

\begin{tabular}{|c|c|c|c|c|c|c|c|c|c|c|c|c|}
\hline \multirow[t]{2}{*}{ Markers } & \multirow{2}{*}{$\begin{array}{l}\text { Marshfield } \\
\text { map } \\
\text { position }^{1}\end{array}$} & \multirow{2}{*}{$\begin{array}{l}\text { deCode } \\
\text { map } \\
\text { position }^{2}\end{array}$} & \multirow{2}{*}{$\begin{array}{l}\text { Physical } \\
\text { map } \\
\text { position }^{3}\end{array}$} & \multicolumn{9}{|c|}{ Lod score at $\theta=$} \\
\hline & & & & 0.0 & 0.01 & 0.02 & 0.03 & 0.04 & 0.05 & 0.1 & 0.2 & 0.3 \\
\hline D6S1708 & 157.84 & not on map & 156072864 & -infini & -1.76 & -1.21 & -0.91 & -0.71 & -0.57 & -0.20 & -0.02 & 0.01 \\
\hline D6S415 & 159.98 & 166.42 & 157748153 & 1.49 & 1.45 & 1.41 & 1.38 & 1.34 & 1.30 & 1.12 & 0.77 & 0.46 \\
\hline D6S437 & 161.59 & 167.04 & 158637457 & -2.64 & -0.88 & -0.61 & -0.45 & -0.35 & -0.27 & -0.07 & 0.02 & 0.01 \\
\hline D6S969 & 161.55 & not on map & 159156005 & -infini & -0.72 & -0.45 & -0.30 & -0.21 & -0.14 & 0.02 & 0.07 & 0.05 \\
\hline D6S1035 & 164.78 & 169.76 & 159900564 & 1.11 & 1.07 & 1.03 & 1.00 & 0.96 & 0.92 & 0.75 & 0.44 & 0.21 \\
\hline D6S1579 & 166.39 & 170.25 & 160897683 & -2.56 & -0.98 & -0.70 & -0.55 & -0.44 & -0.37 & -0.16 & -0.03 & -0.01 \\
\hline D6S305 & 166.39 & NA & 162068740 & -2.56 & -0.98 & -0.70 & -0.55 & -0.44 & -0.37 & -0.16 & -0.03 & -0.01 \\
\hline D6S955 & 167.78 & 173.00 & 162417178 & 1.05 & 1.02 & 0.98 & 0.95 & 0.91 & 0.88 & 0.71 & 0.41 & 0.19 \\
\hline D6S980 & 167.78 & not on map & 162530186 & -1.44 & 0.03 & 0.29 & 0.43 & 0.52 & 0.58 & 0.70 & 0.62 & 0.42 \\
\hline D6S1599 & 169.95 & 174.48 & 162713158 & 3.62 & 3.53 & 3.45 & 3.36 & 3.27 & 3.19 & 2.75 & 1.90 & 1.10 \\
\hline D6S1277 & 173.71 & 176.12 & 164171287 & 2.29 & 2.23 & 2.17 & 2.12 & 2.06 & 2.00 & 1.72 & 1.17 & 0.67 \\
\hline D6S1719 & 177.88 & 178.6 & 165943229 & -infini & -4.09 & -3.20 & -2.67 & -2.30 & -2.02 & -1.19 & -0.49 & -0.20 \\
\hline D6S386 & 182.11 & not on map & 168673727 & 1.00 & 0.96 & 0.92 & 0.89 & 0.85 & 0.82 & 0.65 & 0.37 & 0.17 \\
\hline D6S1027 & 187.27 & not on map & 168930026 & -infini & -3.42 & -2.57 & -2.09 & -1.76 & -1.50 & -0.79 & -0.27 & -0.10 \\
\hline
\end{tabular}

Markers displayed in italic flank the haplotype. Genome scan markers are shown in bold.

Sex-average Kosambi cM map distance from the Marshfield genetic map.

Sex-average Kosambi cM map distance from the deCode genetic map.

Sequence-based physical map distance in bases according to the Human Genome Project - Santa Cruz.

Marshfield genetic map [8]. For the analysis an autosomal recessive mode of inheritance with complete penetrance and no phenocopies was used. A disease allele frequency of 0.001 was assumed. The marker-allele frequencies for the genome scan markers were estimated from the data by means of both observed and reconstructed genotypes of founders from this pedigree and 6 additional large pedigrees from Pakistan which underwent a genome scan at the same time pedigree 4004 was genotyped.

\section{Results}

Analysis of the results obtained from genome search identified an area of interest on chromosome 6q26-q27. Two-point analysis gave a LOD score of 2.3 for marker D6S1277 at recombination fraction 0. A flanking marker D6S1035 spaced at $10 \mathrm{cM}$ proximal to D6S1277 yielded LOD score of 1.1 also at recombination fraction 0 .

In order to fine map the DFNB38 locus, eleven additional markers were selected from the Marshfield map [8]; nine markers are proximal to D6S1277 (D6S1599, D6S980, D6S955, D6S305, D6S1579, D6S969, D6S437, D6S415 and D6S1708) and two are distal (D6S1719 and D16S386). The Marshfield [8] genetic map order for markers D6S437 and D6S969 did not agree with the Human Genome Project-Santa Cruz sequence-based physical map order [9]. Marker D6S969 was not included on the deCode [10] genetic map. In order to confirm that the position of marker D6S437 and D6S969 on the Marshfield map was potentially incorrect, Centre d'Etude du Polymorphisme Humain (CEPH) genotype data was analyzed using MAP-O-MAT [11, 12]. The support for the order of D6S437 and D6S969 on the Marshfield genetic map was low, therefore for multipoint linkage analysis marker D6S437 was removed.

After genotyping the family members with these additional markers, the data was reanalyzed using two-point linkage analysis (table 1) and multipoint linkage analysis. The maximum two-point LOD score occurred at marker D6S1599 with a LOD score of $3.6(\theta=0)$. Multipoint analysis for the family derived a maximum LOD score of 3.6 also at marker D6S1599. The 1-unit support interval ranges from marker D6S980 to D6S1719, a region which is $10.1 \mathrm{cM}$ according to the Marshfield map. In addition, haplotypes were examined to determine the region which contains the DFNB38 locus. A common haplotype that spans a 10.1-cM region between markers D6S980 and D6S1719 segregated in all affected members. The critical recombination events that define the co-segregating interval were observed in hearing impaired individuals. A recombination event can be observed in individual V-1 
that occurred between markers D6S980 and D6S1599. Hearing impaired individuals V-1, V-8, V-13, V-14, V-15 and V-16 are all heterozygous for marker D6S1719, which bounds the telomeric region of the haplotype. The $6 \mathrm{q}$ haplotype for pedigree 4004 is presented in figure 1 . No additional markers are available from either the deCode [10] or the Marshfield [8] genetic maps to further refine the genetic region for the DFNB38 locus.

\section{Discussion}

Large consanguineous families from isolated populations have been instrumental in mapping autosomal recessive hearing impairment loci. In the present study we present evidence for linkage of a novel hearing impairment locus DFNB38 to a 10.1-cM region on chromosome $6 \mathrm{q} 26-\mathrm{q} 27$. It is interesting to note that the 10.1-cM genetic region corresponds to region which is only 3.4 contains MB (table 1) on the Human Genome Project - Santa Cruz sequence-based physical map [9].

In this region of 3.4 MB there are only three known genes which include PARK2 [MIM 602544], PACRG [13] and human phosphodiesterase PDE10A [14]. There is no evidence that these genes would be involved in a hearing impairment phenotype. In addition there are a large number of hypothetical genes within this region.
A number of genes have been identified on chromosome 6 that have been implicated in the etiology of nonsyndromic hearing impairment. Three of these genes are responsible for autosomal dominant hearing loss: EYA4 [MIM 603550], COL11A2 [MIM 120290] and MY06 [MIM 600970]. Mutations within the MYO6 gene are also responsible for autosomal recessive nonsydromic hearing impairment. A fourth gene, GJA1 [MIM 121014] on chromosome 6 is also responsible for autosomal recessive nonsyndromic hearing impairment [3]. Neither the region of homozygosity nor the 1-unit support interval for DFNB38 overlaps with any of these genes. The identification of a gene for DFNB38 is anticipated to broaden our understanding of the molecular basis of hearing.

\section{Acknowledgements}

We wish to thank the family members for their invaluable participation and cooperation. The work was funded by Quaid-I-Azam University Research Fund, Biotechnology Commission Ministry of Science and Technology, Government of Pakistan, the American Hearing Research Foundation and the NIH-National Institute of Deafness and other Communication Disorders grant DC03594. Genotyping services were provided by the Center for Inherited Disease Research (CIDR). CIDR is fully funded through a federal contract from the National Institutes of Health to The Johns Hopkins University, Contract Number N01-HG-65403.

\section{References}

1 Morton N: Genetic epidemiology of hearing impairment. Ann N Y Acad Sci 1991;630:1631.

2 Gorlin R, Toriello HV, Cohen MM: Hereditary hearing loss and its syndromes. 1995;Oxford University press, Oxford.

3 Van Camp G, Smith RJH. Hereditary Hearing Loss Homepage: April 2003 URL: http:// dnalab-www.uia.ac.be/dnalab/hhh/.

4 Heller S, Hudspeth AJ: Two deaf mice, two deaf mice: murine candidate genes pinpoint the genetic bases of nonsyndromic hearing loss in humans. Nat Med 1998;4:560-561.

5 Grimberg J, Nawoschik S, Bellusico L McKee R, Turck A, Eisenberg A: A simple and efficient non-organic procedure for the isolation of genomic DNA from Blood. Nucleic Acid Res 1989; 17:83-90.
6 Cottingham R, Indury RM, Schaffer AA: Faster sequential genetic linkage computations. Am J Hum Genet 1993;53:252-263.

7 Gudbjartsson DF, Jonasson K, Frigge ML, Kong A: Allegro, a new computer program for multipoint linkage analysis. Nat Genet 2002; 25:12-13.

8 Broman K, Murray JC, Scheffield VC, White RL, Weber J: Comprehensive human genetic maps: individual and sex specific variation in recombination. Am J Hum Genet 1998;63: 861-869.

9 International Human Genome Sequence Consortium: Initial sequence and analysis of the human genome: Nature 2001;409:860-921.

10 Kong A, Gudbjartsson DF, Sainz J, Jonsdottir GM, Gudjonsson SA, Richardsson B, Sigurdardottir S, Barnard J, Hallbeck B, Masson G, Shlien A, Palsson ST, Frigge ML, Thorgeirsson TE, Gulcher JR, Stefansson K: A high-resolution recombination map of the human genome. Nat Genet 2002;31:241-247.
11 Lander ES, Green P: Construction of multilocus genetic linkage maps in humans. Proc Nat Acad Sci USA 1987;84:2363-2367.

12 Matise TC, Gitlin JA: MAP-O-MAT: markerbased linkage mapping on the World Wide Web. Am J Hum Genet 1999;65:A435.

13 West AB, Lockhart PJ, O'Farell C, Farrer MJ: Identification of a novel gene linked to parkin via a bi-directional promoter. J Mol Biol 2003; 326:11-19.

14 Fujishige K, Kotera J, Yuasa K, Omori K: The human phosphodiesterase PDE10A gene Genomic organization and evolutionary relatedness with other PDEs containing GAF domains. Eur J Biochem 2000;267:5943-5951.

Ansar/Ramzan/Pham/Yan/Jamal/Haque/ Ahmad/Leal 